https://doi.org/10.18800/iusetveritas.201702.017 (c) (i)

David Friedman $\left.{ }^{*}\right)$

\title{
Mío, tuyo y nuestro: análisis económico del Derecho de Propiedad ${ }^{(* *)}{ }^{(* *)}$
}

\author{
Mine, yours and ours: economic analysis of Property Law
}

\author{
PARA UN NO-ECONOMISTA, LA PRIMERA Y MÁS OBVIA PREGUNTA SOBRE LA PROPIEDAD \\ PRIVADA ES POR QUÉ TENEMOS UNA INSTITUCIÓN TAN ABSURDA. ¿POR QUÉ NO OLVIDAR \\ LAS NOCIONES EGOÍSTAS DE LO TUYO Y LO MÍO, Y DEJAMOS QUE TODOS USEN LO QUE SEA \\ QUE NECESITEN CADA VEZ QUE LO NECESITEN?
}

\begin{abstract}
Resumen: En este artículo, el autor analiza que el sistema de reglas de la propiedad tiene que lograr resultados eficientes y útiles. También, señala las razones de la existencia de la propiedad privada y propiedad pública, luego, explica los costos y beneficios de la propiedad privada, y establece que la diferencia entre la propiedad inmueble y mueble es el sistema de registros. Concluye, afirmando que las cortes creen que un pacto de propiedad es vinculante si es económicamente eficiente.
\end{abstract}

Palabras clave: Análisis Económico del Derecho - Propiedad Privada Propiedad común - Eficiencia - Regla vs. Regulación

\begin{abstract}
In this article, the author analyzes the property legal system has to achieve efficient and useful results. In addition, he points out the reasons for the existence of private property and public property, then he explains the costs and benefits of private property, and he states the difference between real and personal property is the registry system. He concludes by stating the courts believe that a property agreement is obligatory if it is economically efficient.
\end{abstract}

Key words: Law \& Economics - Private Property - Public Property - Efficiency - Rule vs. Regulation

${ }^{*}$ B Bachelor of Arts en la Universidad de Harvard. Master os Arts y Philosophe Doctorate en la Universidad de de Chicago. Profesor de Análisis Económico del Derecho en la Universidad de Santa Clara, de California. Correo electrónico: DDFr@ daviddfriedman.com.

(**) Publicación original: la traducción originalmente constituye el Capítulo 10 "Mine, Thine and Ours: The Economics of Property Law" del libro Law's Order. What Economics Has to Do with Law and Why it Matters (2000) cuyo autor es David D. Fiedman. La traducción estuvo a cargo de Luis Alberto Mena Alferes, egresado de la Facultad de Derecho de la Pontificia Universidad Católica del Perú. Correo electrónico: a20101174@pucp.pe. La gestión para la publicación de la presente traducción fue realizada por Christian Muñoz, estudiante de la Facultad de Derecho de la Pontificia Universidad Católica del Perú y ex miembro de la Comisión de Publicaciones de IUS ET VERITAS.

$\left.{ }^{(* *}\right)$ Nota del Editor: el artículo fue recibido el 30 de mayo de 2017 y su publicación fue aprobada el 17 de junio del mismo año 
Mío, tuyo y nuestro: análisis económico del Derecho de Propiedad

Mine, yours and ours: economic analysis of Property Law

La propiedad parece una idea tan simple: Las cosas les pertenecen a las personas, y el dueño de cada cosa controla como va a ser usada. Al igual que muchas otras ideas simples, esta se torna más y más complicada a medida que uno se detiene a pensar al respecto.

En el capitulo 5 hemos observado algunas complicaciones y vimos como, en principio, uno podría determinar una suma eficiente de derechos de propiedad. En este capítulo, vamos a desarrollar el argumento en dos direcciones: Qué es eso que tiene un propietario, y por qué algunas cosas, propiedad individual, son adueñadas y otras, propiedad común, carecen de dueño.

\section{Haz de derechos: lo que un propietario tiene}

La idea de una cosa perteneciendo a una persona es bastante clara cuando esa cosa es un automóvil o un par de pantalones. Es menos clara cuando la cosa es un pedazo de terreno. ¿Qué derechos me confiere mi titularidad? Con seguridad puedo labrar y cultivar la tierra, o construir sobre ella, o mantener fuera a los intrusos. Pero ¿puedo prevenir que aviones vuelen por sobre ella? ¿Puedo prevenir que mineros escarben túneles por debajo de ella? ¿Qué vecinos emitan ruidos altos cerca de ella? Si es mi predio, ¿eso significa que puedo prohibir que las estaciones de radio transmitan sin mi permiso, bajo la teoría de que si puedo captar la señal, las ondas de radio deben estar traspasando mi propiedad?

Lo que tengo no es una cosa llamada tierra, sino un haz o un cúmulo de derechos. Algunos derechos casi siempre se encuentran en el haz asociado a un pedazo de tierra en particular, tal como el derecho de transitar sobre éste o prohibir que los otros lo hagan. Otros derechos asociados con la tierra, como el derecho a prohibir el paso a intrusos a distintas distancias sobre o debajo de ella y el derecho a que la superficie se mantenga en lugar de deslizarse en la mina de carbón de alguien más, puede o no puede encontrarse en el mismo haz de derechos.

Los capítulos 4 y 5 esbozaron la aproximación económica al diseño de reglas legales eficientes. Esta aproximación parte de dos preguntas: ¿para quién es más valioso un derecho en particular? Y si no lo sabemos con certeza, ¿qué definición inicial de derechos hace que sea más sencillo que estos derechos se trasladen hacia la persona para quien resultan ser más valiosos?

Al construir los cúmulos o haces de derechos a los que nos hemos referido, la primera interrogante se convierte en ¿qué derechos se pertenecen mutuamente? Si soy titular del derecho a labrar la tierra, el derecho a transitar por la tierra vale más para mí que para cualquier otro, entonces ambos derechos pertenecen al mismo haz. Dado que es muy difícil obtener cultivos si otras personas son libres de caminar pesadamente a través de tus campos de cultivo, el derecho a excluir intrusos probablemente pertenezca también a dicho haz. Pero todo ello depende en parte de cómo la tierra va a ser utilizada. Si se desea producir madera en vez de maíz, el argumento no es tan claro. En algunos sistemas legales, la titularidad sobre la tierra implica únicamente un derecho muy limitado a excluir a los intrusos.

El derecho a prohibir que las ondas de radio pasen por sobre mi propiedad, por el contrario, resulta de muy poca utilidad para mi. Si cada propietario de un predio tuviese ese derecho, la instalación de una estación de radio requeriría del consentimiento unánime de cada propietario dentro del radio de transmisión, lo que haría que la transferencia del derecho de los propietarios hacia quien lo valora más sea prohibitivamente complicada. Hace mas sentido tener reglas legales en las que el derecho a transmitir ondas de radio en una determinada frecuencia esté completamente separado de la titularidad de la tierra sobre la cual dicha transmisión pasa. Un argumento similar sugiere que el derecho a prohibir que las aerolíneas traspasen una milla por sobre mi predio sería de muy poco valor para mi, y que mover este derecho a aquellos para quienes tiene mayor valor sería complicado. Ese derecho, también, es excluido del haz.

Un problema más complejo se presenta cuando un derecho singular está asociado con 
David Friedman

dos diferentes, aunque típicamente adyacentes, pedazos de tierra. El derecho a controlar las ondas de sonido que cruzan hacia mi propiedad, a prohibirte reproducir música ruidosa, o a encender fuegos artificiales cerca a mi propiedad a las tres de la mañana, por ejemplo, es valioso para mi. Pero el derecho a controlar las ondas de sonido que cruzan desde tu propiedad, a hacer ruidos que yo pueda escuchar desde mi terreno, es valioso para ti.

El mismo problema se presenta cuando dos propiedades se encuentran adyacentes verticalmente en lugar de horizontalmente. En Pensilvania, un estado construido en buena cuenta a partir de la explotación del carbón, los derechos sobre la tierra están compuestos por tres bienes separables: la superficie, el área del mineral y el área de soporte. Si soy dueño de la superficie y del área de soporte, y tú eres dueño del área del mineral, tú eres libre de minar carbón por debajo de mi predio, pero debes dejar la tierra suficiente para que sirva de soporte de la superficie. Si mi casa colapsa y cae dentro de tu mina, has violado mis derechos. $\mathrm{Si}$, de otro lado, tú eres dueño tanto del área del mineral y del área de soporte, yo puedo ser dueño de la superficie, pero no tengo derecho alguno a que sea soportado por nada. El área de soporte es valiosa tanto para el dueño de la superficie, que quiere algo debajo de su casa que la sostenga, y para el minero, que quiere extraer por allí todo el carbón. Entonces tiene sentido que el sistema legal permita transacciones entre el dueño de la superficie y el dueño de los derechos mineros a fin de aplicar el derecho sobre el área de soporte a quien lo valore más.

El mismo problema se presenta a veces entre vecinos que se encuentran adyacentes horizontalmente. Si excavo un foso muy profundo en mi lado de la línea divisoria de la propiedad, tu terreno puede comenzar a deslizarse hacia el foso. Bajo el common law inglés, el propietario de un terreno tiene el derecho a un soporte lateral, significando ello que su vecino tiene el deber de mantener el soporte que la tierra adyacente hubiese recibido bajo condiciones naturales.

Tales conflictos son materia del Derecho de perjuicios en el common law, área que inspiró el trabajo de Coase. El análisis de las vías férreas y los granjeros en el capítulo 5 fue un bosquejo de como, al menos en principio, las preguntas sobre quién es titular de qué derechos conformantes del haz y sobre cómo dichos derechos podrían ser ejercidos, serían contestadas por un sistema legal eficiente. Hemos de regresar a este tema de nuevo en el capítulo 14.

En el capítulo 5, tras discutir el empleo de reglas de propiedad y de responsabilidad como aproximaciones alternativas para el cumplimiento de derechos de propiedad, mencioné brevemente otra alternativa consistente en el control de la propiedad por el voto de la mayoría. Esta resulta ser una regla común, aunque cuestionablemente eficiente, para el control del uso de recursos minerales fugitivos: el petróleo y el gas.

Considérese un grupo de latifundistas ubicados sobre una gran piscina de petrolero. Si perforo un pozo en mi propiedad y empiezo a bombear, todo el petróleo eventualmente me pertenecerá, pues el petróleo que fluye desde debajo de mi propiedad será reemplazado por petróleo que fluye desde debajo de la tuya (geólogos, incluido aquella con mi encuentro casado, perdonarán, espero, mi sobresimplificación del fenómeno geológico). Mi pozo impone una externalidad sobre ti en la forma de petróleo perdido; tu pozo, si perforas, impondrá una externalidad similar sobre mí. Le interesa a cada persona perforar demasiados pozos y bombearlos demasiado rápido, haciendo que todos empeoremos. Nos encontramos en un dilema del prisionero con múltiples prisioneros.

Una solución es la unificación. En algunos estados, una mayoría suficientemente grande de terratenientes ubicados sobre una piscina de petróleo de este tipo, frecuentemente, dos tercios son requeridos, puede votar para unificar el pozo. Al hacerlo, el petróleo se transforma de propiedad privada de quien tenga el terreno inmediatamente encima de este, a propiedad conjunta de todos los terratenientes. Los terratenientes como conjunto, luego, acuerdan sobre como el petróleo será extraído y comparten el ingreso 
Mío, tuyo y nuestro: análisis económico del Derecho de Propiedad

Mine, yours and ours: economic analysis of Property Law

resultante. Los conflictos de intereses entre los terratenientes son reducidos por reglas legales que requieren tratamiento igualitario; un grupo mayoritario no puede simplemente votar para extraer el petróleo y otorgarle el rédito a sus miembros. Reglas similares prohíben a la mayoría de accionistas en una corporación de transferir los activos de la corporación a su favor actuando a expensas del grupo minoritario de accionistas.

En todos estos casos, las reglas legales relevantes pueden ser pensadas como una forma de definir y agrupar derechos de modo que se logre el resultado más eficiente posible. Si esta aproximación explica las reglas que tenemos o provee razones sobre por qué deberíamos tener reglas diferentes, es menos claro. La conclusión de Coase fue que, en el caso del derecho de perjuicios en el common law, la evidencia sugiere que los jueces estuvieron al menos tratando de producir algo cercano a lo que serían reglas eficientes.

\section{Propiedad individual versus propiedad común}

Para un no-economista, la primera y más obvia pregunta sobre la propiedad privada es por qué tenemos una institución tan absurda. ¿Por qué no olvidar las nociones egoístas de lo tuyo y lo mío, y dejamos que todos usen lo que sea que necesiten cada vez que lo necesiten?

Hay dos razones por las cuales ello no funciona. La primera consiste en que tú y yo no podemos, de manera simultánea, conducir el mismo carro hacia lugares diferentes, ni tampoco puedo conducir mi carro muy lejos si tu uso previo lo ha dejado sin gasolina en el tanque y con un neumático ponchado. Necesitamos una forma de decidir quien usa qué y cuándo, preferentemente en una forma que resulte que la persona para quien algo es más valioso obtenga ese algo. La propiedad privada y el intercambio resuelven ese problema por las razones esbozadas en el capítulo 2 . Si el uso de mi propiedad es más valioso para ti que para mi, estarás dispuesto a ofrecer un precio que yo estaré dispuesto a aceptar.

La segunda razón consiste en que la mayor parte de las cosas que tratamos como propiedad privada son cosas que alguien debe elaborar, y elaborar cosas es costoso. Si elaborar cosas supone ser dueño de ellas, esto te da una razón para seguir elaborándolas. No solo provee un incentivo, sino que provee el incentivo correcto: tu elaborarás algo si y solo si su valor para quien lo valore más, seas tú mismo o la persona a quien planeas vender ese algo, es cuando menos tan alto como el costo de la elaboración. Esta es la regla eficiente.

El rompecabezas para los no-economistas es por qué algo es propiedad privada. El rompecabezas para los economistas es por qué algo no lo es. Habiendo encontrado tan elegante solución al problema de producir y alocar cosas ¿por qué no aplicarla universalmente?

Si piensas que la respuesta es que deberíamos hacerlo, considera extender el derecho de propiedad intelectual para cubrir el leguaje Inglés. Las palabras se convierten en propiedad privada, cada una perteneciendo a su primer usuario o a su heredero o a su encargado. Antes de decir una oración, primero debes obtener los derechos de licencia de cada palabra.

Habría algunas ventajas en establecer propiedad sobre el lenguaje. El dueño de una palabra podría evitar el tipo de sobre uso que deviene en que una palabra se presenta casi sin significado: nice por ejemplo, o awful. Quizás, más importante, proveería un incentivo a los neologismos. El lenguaje inglés carece tristemente de pronombres de genero neutro, dejándonos con la elección entre he-she-or-it, o emplear incorrectamente they para producir barbaridades gramaticales como this policy covers the customer even if they drop dead of a heart attack tomorrow. Si la primera persona en inventar y popularizar un conjunto de pronombres de género neutro eufónico e intuitivo pudiese percibir, a partir de allí, el costo de la licencia de cualquiera que lo utilice, quizás el problema estaría resuelto.

Existen ventajas en establecer propiedad sobre el lenguaje, pero también hay desventajas muy 
David Friedman

grandes. Los costos de transacción asociados a escribir y hablar, en un mundo de palabras privadas, serían muy altos. Sospecho que dichos costos largamente superarían cualquier ventaja derivada de una innovación lingüística más célere. Sería un mundo bastante silencioso.

El argumento no se encuentra limitado a la propiedad intelectual. Consideremos los derechos de propiedad entre pueblos primitivos. Algunos tienen propiedad privada sobre la tierra, otros no. ¿Por qué?

Es tentador responder que aquellos que no tienen propiedad privada sobre la tierra son aun muy primitivos como para haber pensado en esta idea. Sin embargo, esta no puede ser una respuesta adecuada, porque algunos grupos tienen propiedad privada sobre la tierra solo por una parte del año. Ellos conocen el concepto y lo practican a medio tiempo.

Una respuesta más plausible parte de observar que, dado que los pueblos primitivos probablemente sepan más sobre sus condiciones que nosotros, sus reglas legales seguramente sean eficientes en sus circunstancias particulares. Considérese la tierra que es empleada parte del año para la agricultura, y parte del año para la caza de grandes animales a través de ella. La propiedad privada es muy útil para la agricultura, desde que no hay sentido en plantar y desherbar si otras personas son libres de cosechar y alimentarse de esa cosecha. La propiedad privada sobre la tierra en la que se caza, de otro lado, supone detenerse en el borde de cada predio para pedir permiso para cruzar, mientras la presa se desvanece en la distancia. La regla sensata es que el animal que estés cazando sea propiedad privada, perteneciente al cazador que primero lo avistó, mientras que la tierra sobre la que cazas sea de propiedad común. Si los cazadores dependen en el resto de la comunidad para darle cabida a su juego, la regla antes dicha puede ser eficientemente modificada para incluir un derecho a favor de los otros a fin de compartir parte de la caza.

Para un ejemplo menos exótico de tierra bajo propiedad común, considérese los varios tipos de tenencia conjunta o alquiler compartido, tenencia común, tenencia plena, y los intereses vitalicios con reversión que los estudiantes de derecho encuentran al estudiar derecho de propiedad. Todas estas figuras presentan el mismo problema que la propiedad común, el riesgo que cada parte, al decidir sobre como usar la tierra, vayan a ignorar los intereses de los demás. Las doctrinas legales, tales como el derecho de desperdicio, que prohíbe alterar la propiedad de modo lesivo a los intereses de la persona en cuyo favor se ha de revertir la propiedad, han evolucionado como intentos del common law para lidiar con este problema.

Un ejemplo más reciente de propiedad común lo constituye la información en Internet. Mientras que algunos proveedores eligen cobrar por información, otros, yo entre ellos, deliberadamente la entregan a quien lo solicite. Y el procedimiento estándar para que el e-mail de la computadora A llegue a la computadora $G$ a través de las computadoras intermedias $\mathrm{B}-\mathrm{F}$, no involucra ningún cargo por parte de los propietarios de las computadoras intermedias a los propietarios de las computadoras cuyo e-mail están reenviando.

Cobrar por la información en línea, aunque posible, es costoso, con el resultado que los sitios pornográficos lo hacen y al resto de nosotros no nos molesta. En cambio, confiamos en formas indirectas de obtener un pago por la información que regalamos: publicidad para otros sitios comerciales, el placer de difundir nuestras ideas, así como presumir fotos de nosotros y de nuestros hijos para sitios no comerciales. Ello funciona porque el costo de distribuir información, medida por usuario, es lo suficientemente bajo para ser cubierto por tales métodos indirectos. Cobrar por reenviar los paquetes de información en los que un e-mail se disuelve cuando deja la computadora servidor, requeriría de un enorme número de pequeños cobros, actualmente un procedimiento irrazonablemente costoso (aunque ello pueda estar cambiando). En cambio, la regla base para las computadoras servidor es reenviaré tus paquetes si tu reenvías los míos.

Hay muchos ejemplos de firmas que rutinariamente regalan cosas. Un restaurante de todo lo que puedas comer cobra por 
Mío, tuyo y nuestro: análisis económico del Derecho de Propiedad

Mine, yours and ours: economic analysis of Property Law

entrada, pero una vez dentro la comida adicional es gratis. Muchos proveedores de Internet siguen la misma política, un precio fijo mensualmente a cambio de un servicio ilimitado. Podamos o no explicar el fracaso de los pueblos primitivos en mantener derechos de propiedad sobre la tierra a partir de la simple ignorancia, no podemos recurrir a esta explicación para analizar la política de precios de AOL. Una explicación más plausible consiste en que tales firmas están balanceando la ineficiencia producida por el sobre uso, una comida adicional que vale para ti diez centavos y que cuesta veinte centavos al restaurante producir, contra los costos ahorrados de no tener que restringir y monitorear el consumo.

Estos ejemplos sugieren una razón por la que la propiedad privada a veces no amerita ser empleada: los costos de transacción de trasladarla de una persona a otra. Esta es la explicación obvia de por qué no queremos que las palabras del idioma Inglés sean privadas. Una segunda razón está en el costo y en la dificultad de reconocer y definir los límites, lo que me lleva a la historia de la isla flotante.

\section{La Isla Flotante}

La Stack Island en el río Mississippi le pertenecía a alguien. Con el transcurso de muchos años, el río erosionó la zona ubicada en el extremo norte de la Stack Island y depositó sedimento en su extremo sur, generando que la Stack Island gradualmente fuese arrastrada río abajo.

A cierta distancia de la Stack Island, el banco oeste del río le pertenecía a alguien más, junto con todas las islas ubicadas en el río al este de su propiedad. Después de un tiempo, entre estas islas se encontraba la Stack Island. ¿A quién le pertenecía?

El proceso judicial resultante fue resuelto sobre la base de la prescripción adquisitiva: La corte, sosteniendo que el propietario de la rivera costera había esperado mucho tiempo para ejercitar sus derechos, evitó pronunciarse sobre si realmente tenía algún derecho que ejercitar. Lo que disfruto del caso es que ilumina una de las asunciones implícitas en el derecho de propiedad, que los límites se quedan donde se los trazó, permitiéndonos definir lo que tenemos de manera meridiana. Los derechos de propiedad que entraron en conflicto en el caso referido, estuvieron definidos de manera perfectamente clara y sensata en tanto las islas se quedasen donde se encontraban. En un mundo en el que la Stack Island fuese la norma y no la excepción, donde los límites físicos que definen los derechos de propiedad cambiasen sin anticipación y de manera ambigua, definir dichos límites o bordes, y arbitrar las disputas resultantes, puede constituir un costo significativo en el mantenimiento del sistema de propiedad privada.

Considérese la siguiente descripción del derecho de tierras en Sudan:

"No se puede comprender un caso de tierras sobre el Nilo sin entender cómo el río se comporta. Mientras que el caudal se eleva y disminuye en su ciclo anual, la tierra fértil del lecho rivereño es cultivable por siete u ocho meses, luego desaparece sumergida bajo el agua. Un año puede ocurrir que un tramo en particular no reaparezca, y el propietario pierda su tierra. Cinco años más tarde dicho tramo reaparece en el mismo lugar. ¿El antiguo propietario aun tiene derechos sobre el predio? Si está muerto, ¿Quién tiene los derechos sobre el predio? Quizás una isla se haya desvanecido tras la inundación. Reaparece un cuarto de milla corriente abajo con una forma ligeramente distinta. ¿El propietario de la antigua isla es propietario de la nueva? Las orillas del Nilo también ocasionalmente tienden a balancearse hacia delante y detrás, y, de acuerdo a la costumbre que prevalece en la mayor parte de lugares, a medida que las orillas se mueven, lo hacen también la tierra rivereña. La propiedad de todos oscila con el río. Inclusive las personas cuya tierra se encuentra ubicada a alguna distancia del agua se ven afectadas cuando el canal cambia de dirección. Las propiedades cercanas y lejas se mueven como piezas conectadas de una armadura, en concierto con la impredictibilidad del agua" ( McPhee, John:162). 
David Friedman

Sobre este tópico regresaremos en el próximo capítulo. En el derecho de la propiedad inmueble los límites difusos son una excepción. En el derecho de patentes, que se ocupa de delimitar los límites entre ideas, ellos son la norma.

\section{Por qué les debemos la civilización a los perros}

La fecha es 10000.00 o 11000.00 A.C. Eres miembro de una tribu primitiva que cultiva su tierra bajo un sistema de propiedad común. Cultivar la tierra en propiedad común es un martirio; la tribu tiene que pasar casi tanto tiempo vigilándose el uno al otro y discutiendo sobre quien está o no está haciendo su parte, como el que invierten arando la tierra con palos o ramas puntiagudas y eliminando la maleza.

Son primitivos pero no estúpidos, los estúpidos no viven lo suficiente en tu entorno, y se les ha ocurrido a varios de ustedes que el problema desaparecería si convirtiesen la tierra común en propiedad privada. Cada persona cultivaría su propia tierra; si tu vecino elige no trabajar lo suficientemente duro, serán él y sus hijos, y no tú y los tuyos, quienes sufrirían hambre.

Había un problema con esta solución, uno que observaron cuando un vecino intentó implementarla algunos años atrás. La propiedad privada no se cumple por sí misma. Alguien más tiene que asegurar que el vecino holgazán no solucione su falta de comida a tus expensas. En vez de gastar tus días asegurándote que tus compañeros de la tribu estén trabajando con empeño en el cultivo de la tierra común, vas a pasar tus noches asegurándote que no están trabajando empeñosamente sobre tus cultivos. Con todo esto, concluyen que el cultivo comunal es la solución menos mala.

Las tierras de cultivo siguen siendo tratadas como comunes por otros cientos de años, hasta que alguien realiza un avance tecnológico radical: la domesticación del perro. Los perros, siendo animales territoriales, pueden ser entrenados para identificar la tierra de su dueño como su territorio y responder apropiadamente contra los invasores. Ahora sí pueden convertir la tierra de cultivo en propiedad privada y dormir pacíficamente. Piénsese en esta solución como una alarma biónica antirrobos.

No recuerdo quien fue el que propuso esta explicación para el surgimiento de la propiedad privada de la tierra, y no sé lo suficiente de antropología y prehistoria para juzgar cuan plausible es. Pero, si non e vero, e ben trovato (si no es cierto, debería serlo). Tal como la historia de la isla flotante simboliza convenientemente el problema existente la definición de límites, la historia de la alarma antirrobos biónica, y de cómo le debemos un paso crucial en la civilización humana al perro, simboliza el problema de hacer efectivos esos límites y el hecho de que si hacerlos efectivos resulta muy costoso quizá no valga la pena hacerlo. Este tema también será revisado en el siguiente capítulo, donde veremos cómo los cambios tecnológicos nos han llevado de un mundo donde las editoriales podían hacer cumplir con éxito derechos que, legalmente hablando, no tenían, a un mundo en el que se encuentran impedidos de hacer efectivos derechos que, legalmente hablando, sí tienen.

\section{5. ¿El error más caro que el gobierno norteamericano alguna vez cometió?}

Hasta ahora hemos discutido los problemas asociados a la definición de la propiedad y al cumplimiento de los derechos de propiedad. Sin embargo, se presentan problemas adicionales con la creación inicial de derechos de propiedad, el proceso que determina quién tiene qué.

Como muchas cosas que discutiremos, los incentivos para adquirir derechos de propiedad a veces es un error y a veces un atractivo. En el caso de cosas cuyo valor es creado a través del esfuerzo humano, es un atractivo; el hecho que obtengas la propiedad de un carro por haberlo construido, proporciona un incentivo para que la gente construya carros.

En el caso de tierras, de otro lado, muchas de las cuales constituyen bienes que no son creados a través del esfuerzo humano, los incentivos asociados a la creación de derechos de propiedad pueden tener consecuencias menos atractivas. Considérese las implicancias 
Mío, tuyo y nuestro: análisis económico del Derecho de Propiedad

Mine, yours and ours: economic analysis of Property Law

económicas establecimiento de asentamientos rurales, mecanismo a través del cual grandes áreas de tierra pública en los Estados Unidos se convirtieron en propiedad privada. Bajo la Homestead Act de 1862, un colono obtenía propiedad sobre una milla cuadrada de tierra, 160 acres, por cultivarla por un número de años determinado y por el cumplimiento de una serie de requisitos tales como sembrar árboles frutales en ella.

El año es 1862, la porción de tierra sobre la que nos centramos se encuentra alejada de los límites del asentamiento más cercano, muy lejos de las vías del tren, de las tiendas de abarrotes y comida, y, en general, del resto de personas como para que sea cultivada con algún beneficio. A medida que el tiempo pasa y los límites de los asentamientos se expanden, la situación cambia. La regla eficiente sería iniciar con los cultivos de la tierra el primer año en el que dicha actividad sea rentable, digamos en 1890.

Pero si decides asentarte en la tierra en 1890, te vas a llevar una sorpresa desagradable; alguien más ya está allí. Asentar las tierras que ya son rentables para cultivar es una propuesta atractiva, pues no solo generas dinero en el proceso, sino que también terminas con bienes raíces valiosos. Cuando derechos valiosos se adjudican de manera gratuita, no hay escasez de interesados. Si quieres obtener la tierra, tendrás que llegar antes. Cultivando la tierra en pérdida durante unos cuantos años, puedes adquirir el derecho a cultivarla de manera rentable en lo sucesivo.

¿Cuán temprano tendrías que llegar? Para simplificar las cosas, asumamos que el valor de la tierra en 1890 va a ser veinte mil dólares, representando el valor presente de la ganancia que se puede obtener de cultivarla desde entonces. Asimismo, asumamos que el valor de la pérdida derivada de cultivarla previamente a dicha fecha es de mil dólares por año. Si intentas afincar la tierra en 1880, nuevamente la encontrarás ya ocupada. Alguien que afinca en 1880 paga diez mil dólares a cambio de veinte mil dólares en bienes raíces (no es tan bueno como obtenerla gratuitamente, pero sigue siendo un negocio atractivo). Siguiendo la lógica del argumento, concluimos que la tierra sería ocupada alrededor de 1870, lo suficientemente temprano como para que las pérdidas de los primeros años sean balanceadas por las ganancias posteriores. Se sigue de lo dicho que el efecto de la Homestead Act fue la eliminación, en los costos de cultivos prematuros, de una gran parte del valor de las tierras de los Estados Unidos.
Si piensas que este argumento se hace familiar, estás en lo correcto. La lógica del asentamiento es la misma lógica que subyace al robo, discutida en el capítulo 3; ambos son ejemplos de búsqueda de rentas. El ladrón gasta recursos en tiempo y esfuerzo de modo que él, antes que tú, termine en posesión de tu equipo de televisión. Quien decide asentarse en un predio rural, gasta recursos a fin de que él, antes que el siguiente posible solicitante, termine poseyendo un pedazo de tierra en particular. En ambos casos, los actores involucrados están compitiendo el uno con el otro para obtener algo valioso que ya existe $y$, en el proceso de hacerlo, gastan recursos aproximadamente iguales al valor de lo que obtienen.

En este caso, así como en el otro, un análisis completo sería en algún modo más complicado. Algunas personas son mejores en instalarse en un predio que otras, tal y como algunas personas son mejores robando que otras. En equilibrio, el colono marginal o el ladrón marginal culminan sin pérdidas ni ganancias. Solamente el colono o ladrón habilidoso, según sea el caso, genera réditos. Se sigue de lo dicho que el afincamiento no disipa la totalidad del valor de la tierra, sino únicamente una gran parte de este.

\section{O quizás no - En defensa del afincamiento}

Terry Andersen y P.J. Hill, los economistas cuyo argumento he resumido, concluyen que lo que el gobierno debería haber hecho es subastar la tierra. De este modo, los gastos realizados por los colonos en busca de rentas habrían sido dirigidos a pagar las cuentas del gobierno federal en vez de ser desperdiciados produciendo cultivos que no cubren sus costos de cultivo y tratando de mantener árboles frutales en lugares naturalmente destinados a ser praderas. Lo que no explicaron fue por qué el gobierno, que mantenía el dominio sobre la 
David Friedman

tierra y, en ese entonces como ahora, siempre tuvo usos para el dinero en efectivo, no siguió el método antes dicho.

La respuesta es que el gobierno lo intentó. Poco después de la Revolución, hubo intentos repetidos, tanto de parte de los gobiernos estatales como federales, para obtener dinero a partir de la subasta de tierra de dominio público. Pero había un problema.

El gobierno federal ha anunciado que un territorio en particular va a ser abierto al público, con subastas llevadas a cabo localmente a fin de permitir a los compradores inspeccionar la tierra sobre la que van a ofertar. Como representante de un sindicato de bienes raíces en Boston, te diriges al Viejo Oeste, hacia algún lugar en lo que será el este de Ohio, a comprar tierras.

Para tu sorpresa descubres que, pese a la tierra aun no había sido abierta para su adjudicación, ya se encuentra tomada. La mayoría de personas presentes en la subasta, realizada a noventa millas de la nada, son ocupantes o colonos ilegales que ofertan por tierras que ya se encuentran cultivando, hombres de frontera con cuchillos en sus botas y rifles de pedernal apoyados contra la pared.

Ellos te dejan en claro que al margen de lo que pase en el este, aquí, ofertar en contra de un colono por su tierra simplemente no va a suceder, dejando a tu imaginación lo que te puede ocurrir en caso decidas hacerlo. Cada colono ilegal termina comprando una milla cuadrada de tierra, la mejor tierra que pudieron encontrar cuando llegaron y se instalaron años atrás, a un precio mínimo en la subasta debido a que nadie más va a ofertar por su tierra. Todo lo que queda para ti es la tierra que nadie más quiere.

En algunos casos el proceso era aún más simple. Cuando la tierra iba a ser abierta para su colonización, las personas que ya se encontraban viviendo allí solicitaban su titularidad al Congreso, arguyendo que, como hombres de frontera valientes, se encontraban en posición de recibir un tratamiento especial. El gobierno podía obtener ingresos subastando otras tierras a otras personas, pero ellos contaban con el derecho a comprar la tierra en la que se habían instalado al menor precio legal. Con frecuencia esto funcionaba. Los colonos, inclusive los ilegales, eran también votantes.

Como sugieren estos ejemplos, de algún modo estilizados a partir de la historia real, las ventas de tierra bajo ley resultaban, en la práctica, en el mecanismo de asentamiento, lo cual podría constituir la razón por la cual el gobierno federal se dio por vencido y llevó el asentamiento a la ley.

Como nota final en defensa del asentamiento, existe la posibilidad que los colonos ilegales estuviesen en lo correcto y los economistas equivocados. Dichos colonos, después de todo, realmente fueron hombres de frontera sagaces y corajudos. Una de las cosas que hicieron al instalarse en estas tierras fue ayudar a mantener o consolidar el dominio de los Estados Unidos sobre las tierras en contra tanto de los habitantes nativos como de gobiernos rivales al norte y al sur. Un modo de defender el asentamiento consiste en argumentar que el otorgar a los colonos un derecho sobre la tierra en la que se instalan, así como otorgar a las compañías automovilísticas un derecho sobre los autos que producen, en realidad generó un incentivo útil, no a fin de crear la tierra, sino para aventurarse al exterior y defenderla. Desde el punto de vista del gobierno que otorgó las tierras, el asentamiento era una actividad productiva. Desde un punto de vista más general, uno que tome en cuenta en cuenta en el cálculo de la eficiencia económica los intereses de los canadienses, mexicanos y los indígenas nativos americanos, aun se trata de un caso de búsqueda de rentas, pero a mayor escala.

Se trate o no de una defensa plausible de lo que ocurrió, la lógica del asentamiento ineficiente, la historia de Hill y Andersen sobre cómo el gobierno aplastó el valor de las tierras públicas, nos proporciona una razón adicional sobre por qué convertir algunas cosas en propiedad privada no siempre es una buena idea. Retornaremos a este tema en el siguiente capítulo, donde consideraremos al Derecho de propiedad intelectual como una forma de constituir propiedad sobre bienes intelectuales sobre los cuales no existía propiedad alguna 
Mío, tuyo y nuestro: análisis económico del Derecho de Propiedad

Mine, yours and ours: economic analysis of Property Law

y veremos bajo qué circunstancias el resultado califica como búsqueda de renta ineficiente.

\section{Por otro lado: los beneficios de la propiedad privada}

Hasta ahora hemos visto los costos de tratar las cosas como propiedad privada, los problemas derivados de su defensa, de su eficacia o cumplimiento, y de las transacciones sobre los derechos de propiedad. Si vale la pena asumir estos costos depende de cuan cuantiosos sean los beneficios que fluyen de los incentivos para una producción y adjudicación eficiente creados con la propiedad privada.

Supón que estás convencido que, inclusive sin que existan derechos de autor, se van a escribir novelas en abundancia. Los grandes escritores, sostendrías, no están motivados por el dinero, sino por el deseo de fama y grandeza o por el amor a su arte. Como evidencia, señalas cómo buena parte de la mejor literatura universal, incluidos los trabajos de Homero, Dante y Shakespeare, preceden a la existencia de derechos de autor.

Si este argumento es correcto, entonces los incentivos para producir propiedad a fin de ser titular de esta no resultan de mucha importancia en el caso de la literatura, lo que debilita el argumento que apoya a los derechos de autor. La segunda ventaja de los derechos de propiedad consiste en la mejor adjudicación de los bienes existentes, y dado que el hecho que yo lea una novela no excluye que tú también leas la misma novela, la adjudicación no es un problema en el caso de la literatura. No podemos conducir el mismo automóvil en dirección a distintos lugares, pero podemos leer simultáneamente (diferentes copias de) la misma novela. Y lo que el derecho de autor trata como propiedad es la novela, la secuencia de palabras, no el libro físico. El libro sería propiedad privada incluso sin que existan derechos de autor.

Para expresar el argumento en términos un tanto más técnicos, el beneficio derivado de un incentivo de producción adicional depende de la elasticidad de la oferta, de cuan sensible es la cantidad producida respecto del precio que el productor obtiene por producirla. Si la oferta es muy inelástica, entonces los incentivos no importan mucho, de modo que obtienes casi tantas novelas sin que existan derechos de autor como si existiesen. Si la oferta es muy elástica, de otro lado, la eliminación de los derechos de autor resultaría en una reducción dramática en la producción de literatura nueva.

Un argumento similar se aplica para el lado de la demanda. Considérese un restaurante de formato todo lo que puedas comer. Si sirve ensaladas, el que cada porción adicional sea gratis resultara únicamente en una ineficiencia menor. Las porciones adicionales le cuestan al restaurante veinte centavos por plato, pero no me cuestan nada como consumidor; subestimarlos por veinte centavos causa únicamente un incremento modesto sobre cuanto voy a consumir. $Y$ mi consumo extra como comensal, aunque ineficiente, no es tan ineficiente; en el peor de los casos, estoy consumiendo una porción de ensalada que me ha costado alrededor de un centavo y le ha costado al restaurante veinte centavos, por una pérdida de eficiencia neta de diecinueve centavos.

En contraste con lo dicho está el caso de un restaurante de sushi bajo el mismo formato (en mi experiencia, una institución mucho más extraña). Hacer sushi es un trabajo que requiere de una destreza especial, de modo que las porciones individuales son, como consecuencia, bastante caras. Dejar que el precio que pago por cada porción adicional descienda de tres dólares a cero, resultaría en mi salida del restaurante ineficientemente satisfecho. Y la última porción de sushi que coma antes de rendirme a los límites geométricos de mi estomago representarían una pérdida de eficiencia de alrededor de $\$ 2.99$.

De este modo, al decidir si vale la pena convertir algo en propiedad, debes considerar dos cuestiones distintas. ¿Cuán grandes son, para este tipo particular de cosas, los costos asociados a su trato como propiedad privada antes que como propiedad común? ¿Cuán fácil es definir los límites, hacer efectivos los derechos de propiedad y transar sobre los 
David Friedman

mismos? ¿Cuán sensibles son los productores y consumidores al incentivo perverso que genera un precio cero?

\section{Propiedad inmueble y propiedad no inmueble}

Toda propiedad consiste en un haz de derechos en relación a las cosas. Pero la propiedad sobre la tierra, conocida en derecho como propiedad inmueble, tiene características especiales, en gran medida, los propietarios son libres de reagruparla. Le puedo vender a mi vecino una servidumbre, como el permiso a cruzar por mi propiedad. Una vez que lo he hecho la servidumbre no es meramente un contrato entre él y yo, sino, como cualquier otra propiedad, un derecho oponible frente al resto. Si vendo mi propiedad a alguien más, la servidumbre también lo vincula, inclusive si esta persona nunca la aceptó y quizá nunca tuvo conocimiento de su existencia. Esta característica del Derecho de propiedad, hace que sea más fácil para los propietarios de predios adyacentes coordinar sus actividades. Habiendo adquirido una servidumbre para cruzar tu predio, puedo construir una nueva casa sin preocuparme que un futuro propietario pueda retirar el permiso, dejándome varado.

Supongamos, por otro lado, que te vendo un carro. Como un miembro de una particular secta de Judaísmo Ortodoxo extremo, tengo la convicción de que no solamente no debo trabajar durante el Sabbath, sino que mi carro tampoco debe trabajar o ser usado durante el Sabbath. De este modo, una de mis condiciones para la venta, a la cual tú accedes, es que, desde el momento en el que el sol se pone el viernes hasta el momento en el que el sol se pone el sábado, el carro no deberá ser conducido.

Esa condición es un contrato exigible en contra tuyo. Pero si le vendes el carro a alguien más, dicha condición no resulta exigible frente a esta persona. Yo podría haber estipulado en el contrato original que solamente venderías el carro a quien acepte el acuerdo antes descrito, sin embargo, tal estipulación solamente te vincularía a ti y no así al nuevo comprador. Te podría demandar por incumplir nuestro contrato, pero no puedo frenar al nuevo propietario de tomar un paseo en el automóvil un sábado.

Hay una simple y obvia razón para la diferencia entre la propiedad inmueble y todo lo demás. La titularidad sobre la tierra es controlada por un elaborado sistema de registro, involucrando títulos de propiedad, registros de predios, y demás similares. Las restricciones tales como la servidumbre que soporta la tierra son parte de dicho sistema, de modo que un comprador diligente, de hecho, tendría conocimiento acerca de la servidumbre. El comprador diligente de un carro sabría si este se encuentra gravado por algún préstamo, dado que esta carga se encuentra incluida en nuestro sistema de registro de títulos, pero ello es todo lo que sabría. Un comprador diligente de otros bienes ni siquiera sabría ese tanto.

Para poner el mismo argumento en términos utilizados previamente en este capítulo, la Stack Island es una excepción a la regla. En su mayoría, para la propiedad inmueble es fácil dibujar líneas limítrofes alrededor de la tierra. No solo es fácil dibujar los límites físicos de un pedazo de tierra, sino también, gracias al sistema de registro, es fácil dibujar los límites alrededor del haz de derechos que el propietario mantiene respecto a ese pedazo de terreno, límites que otras personas pueden, si así lo quieren, observar. Por lo tanto, es práctico permitir un grado considerable de reagrupación. El argumento a favor de ello se encuentra implícito en varias de las flechas contenidas en el diagrama de spaghetti del capítulo 5 . El permiso para lanzar chispas es una servidumbre.

La propiedad sobre otras cosas también opera frente al resto del mundo, pero viene en una versión de talla única. $O$ eres propietario de algo o no lo eres. El comprador de bienes robados, como regla general, no tiene un buen título, aunque existen excepciones. Pero el comprador de algo cuyo uso se encuentra afectado por un contrato, por ejemplo un contrato que impide utilizar ese algo un sábado, sí tiene un buen título. El título de propiedad es efectivo contra el mundo; las obligaciones contractuales son efectivas contra la persona que firmó el contrato. 
Mío, tuyo y nuestro: análisis económico del Derecho de Propiedad

Mine, yours and ours: economic analysis of Property Law

Si nuestra disposición a permitir la reagrupación de la propiedad inmueble se debe a un sistema registral que hace posible para terceros compradores tomar conocimiento sobre qué están adquiriendo, una implicancia de ello es que la posibilidad de reagrupar el haz de derechos debe ser limitada por la posibilidad de los terceros de enterarse al respecto. En términos generales, esto es así. Como regla general, una servidumbre es vinculante para sucesivos compradores solamente si su existencia pudo ser deducida, o cuando menos sospechada, de la inspección sobre el predio o si una búsqueda prudente en los registros relevantes hubiese revelado esta situación.

\section{Regla versus regulación: La doctrina del tacto y la preocupación}

"Una servidumbre... es inválida si la restricción es irrazonable. La razonabilidad es determinada comparando la utilidad de la restricción frente a las consecuencias perjudiciales de hacer cumplir la restricción"(2).

El haz de derechos que conforman la propiedad pueden ser reagrupado, haciendo posible crear derechos asociados a la tierra oponibles frente a futuros dueños. Tales derechos incluyen no solo a las servidumbres, como el derecho a cruzar por el predio, sino también licencias, como el derecho a utilizar el predio, para cazar o para realizar actividad minera por debajo de este. Estos también incluyen convenios que se asocian al predio, tales como acuerdos que establezcan que en un proyecto de desarrollo residencial los predios solamente serán utilizados con fines residenciales y no comerciales, los equivalentes privados a la regulación zonal. Un cuerpo legal elaborado determina bajo qué circunstancias tales acuerdos son oponibles frente a quienes.

Una característica interesante de ese cuerpo legal es que, pese a que los detalles varían con el tiempo y respecto de cada jurisdicción en particular, generalmente más fácil transmitir un beneficio al futuro comprador que un perjuicio. Supongamos que he celebrado un convenio legalmente vinculante con mi vecino, en virtud del cual hemos acordado que no voy a construir una fábrica en un sector mi predio cercano a su residencia. Bajo este escenario, es más probable que la venta de mi predio extinga dicho convenio, dejando a mi vecino sin recurso alguno contra el nuevo propietario, que lo es el que la venta de su predio sea la que extinga el convenio, dejando al nuevo propietario sin recurso frente a mí.

Hay una razón económica para este patrón. La posibilidad de modificar o reagrupar el haz de derechos hace sentido debido a la habilidad o posibilidad de los compradores para conocer lo que están comprando. Si tú estás vendiendo un predio con un beneficio asociado, el derecho a que tu vecino no haga cosas que reduzcan el valor del predio, tienes todas las razones para contarle a tu comprador al respecto. Si, en cambio, estoy vendiendo un predio con una carga asociada, una obligación de no usar el predio en cierto modo que el nuevo propietario podría querer utilizar, tengo un incentivo para no contarle nada al comprador. Así que los requisitos legales que definen, en términos generales, cuan obvia debe ser la existencia del convenio a fin de vincular al nuevo propietario son más estrictos cuando se va a transmitir una carga que lo que son cuando se va a transmitir un beneficio.

Un segundo problema se presenta cuando reestructuramos los derechos sobre un predio es, justamente, qué derechos pueden ser incluidos en ese haz. Si no existe restricción alguna, entonces todos los derechos se vuelven reagrupables o reestructurables. Todo lo que debo hacer es fusionar mi titularidad sobre mi carro con mi titularidad sobre un predio, haciendo que todos los derechos asociados a ambos bienes se compaginen en un haz común de derechos. De este modo, dado que ese haz constituye un grupo de derechos asociados a la propiedad inmueble, puede ser a su vez reagrupado. Entonces, separo el derecho a manejar el auto seis días a la semana y te lo vendo, reteniendo el derecho a manejar, o no manejar, el carro los días sábado.

(2) Restatement (Third) of Property, Servitudes, cap. 3.4, 1991. 


\section{David Friedman}

El common law previno tales malabarismos requiriendo que cualquier pacto que estuviese asociado al predio deba involucrar una carga o un beneficio que recaiga o concierna a dicho predio. Tu sábado manejando el carro que te vendí no recae o concierne a mi predio, por lo que ese derecho no se puede asociar al predio.

¿Y si te vendiese una porción de mi predio, junto con un pacto en virtud del cual yo accedo a proveerte agua de mi pozo, y tú accedes a comprarla bajo un precio fijo? El acceso al agua puede ser relevante sobre el valor de tu predio, de modo que tu derecho a conseguirla concierne al predio que compraste. Pero una vez que decides perforar tu propio pozo, ¿mi derecho a que me paguen por el agua que ya no quieres comprar aún se encuentra asociado a tu predio?

Las cortes modernas en cierta medida han abandonado esta doctrina en favor de la regla citada al inicio de esta sección: los pactos son vinculantes si son razonables. En términos generales, esto significa que son vinculantes y oponibles si la corte cree que son económicamente eficientes y, de lo contrario, inaplicables o inejecutables.
En el capítulo 4 señalé dos formas diferentes en las que una corte podría lidiar con externalidades. Podría decidir en cada caso qué parte es la lowest-cost avoider del problema y asignar derechos de acuerdo a un análisis caso por caso, o podría establecer reglas generales diseñadas para resolver problemas de la manera más eficiente posible. La misma cuestión se presenta aquí. La vieja aproximación al problema consistía en utilizar una regla general, la doctrina del tacto $y$ preocupación, para ayudar a determinar si un pacto era un mero contrato entre dos partes o formaba parte de la propiedad sobre la tierra, y consecuentemente para determinar qué derechos podían ser reagrupados. La nueva aproximación al problema se acerca a la determinación judicial caso por caso sobre si la reagrupación es o no deseable.

Una razón para el cambio puede haber sido que la regla con la que el common law lidiaba con esta situación no servía muy bien a la función de una regla en sí, era lo suficientemente vaga como para que las partes se enfrentasen a una considerable incertidumbre acerca de si las cortes habría o no de hacer cumplir los pactos particulares. Resta por ver si el nuevo enfoque funcionará mejor.

\section{Referencias Bibliográficas}

McPhee, John. 1968. A Roomful of Hovings and other profiles. New York: Farrar Straus \& Giroux. En la parte que cita a Carroll W. Brewster. 